\title{
ROLE OF CHLOSITE GEL DELIVERY IN THE MANAGEMENT OF AGGRESSIVE PERIODONTITIS ATTENDING THE OUTPATIENT DEPARTMENT OF DENTISTRY, VARUN ARJUN MEDICAL HOSPITAL, BANTHRA, SHAHJAHANPUR (U. P.)- A PILOT STUDY
}

\author{
Keerti Sharma1, Karthik Krishna M², Rohit Jain³, Manjesh Kumar
}

${ }_{1}^{1}$ Assistant Professor, Department of Periodontology, Varun Arjun Medical Hospital, Banthara, Shahjahanpur, Uttar Pradesh, India.

2Professor, Department of Periodontology, TMDCRC, Moradabad, Uttar Pradesh, India.

${ }_{3}^{3}$ Assistant Professor, Department of Periodontology, TMDCRC, Moradabad, Uttar Pradesh, India.

${ }_{4}^{4}$ Statistician, Department of Periodontology, Varun Arjun Medical Hospital, Banthara, Shahjahanpur, Uttar Pradesh, India.

\begin{abstract}
BACKGROUND
ABSTRACT

Periodontitis is an immune-inflammatory disease of the tissues surrounding the teeth. Various treatment modalities like mechanical debridement and use of antimicrobials have been followed in such conditions. Introduction of local drug delivery system in the periodontal pocket is a promising therapeutic modality for achieving better clinical outcomes when used as an adjunct to conventional non-surgical periodontal therapy. It was in the year 1979, Dr. Max Goodson et al first proposed the concept of controlled delivery in the treatment of periodontitis. So, the present study was designed to evaluate the clinical effects of topical application of Xanthan gel (chlorhexidine coadjuvant) in the treatment of aggressive periodontitis.

The present study was designed to evaluate the clinical effects of topical application of Xanthan gel (chlorhexidine coadjuvant) in the treatment of aggressive periodontitis.
\end{abstract}

\section{MATERIALS AND METHODS}

This study was carried out on 5 patients (Aged 25 - 40) with aggressive periodontitis. They received root planning and curettage alone on one side and Xanthan gel (Chlorhexidine coadjuvant) on the other side. Each individual was subjected to the following measurements: (1) Evaluation of the clinical parameters pre- and post-treatment to detect the outcome of the treatment modality or at 1, 3 and 6 months were obtained for microbiological evaluation.

\section{RESULTS}

1. Xanthan gel delivered locally into periodontal disease sites reduced all subgingival bacteria, and

2. Both treatments and modalities led to statistically significant reduction in microbiological counts as well as clinical parameters applied.

\section{CONCLUSION}

The results showed that syringe of Xanthan gel with root planning and curettage and levelling of the root surface resulted in a greater improvement in periodontal clinical indices than root planning alone.

\section{KEY WORDS}

Xanthan Gel, Antimicrobial Agents, Aggressive Periodontitis, Root Planning and Curettage.

HOW TO CITE THIS ARTICLE: Sharma K, Krishna KM, Jain R. etal. Role of chlosite gel delivery in the management of aggressive periodontitis attending the outpatient department of dentistry, Varun Arjun Medical Hospital, Banthra, Shahjahanpur (U. P.)- a pilot study. J. Evolution Med. Dent. Sci. 2018;7(26):3045-3048, DOI: 10.14260/jemds/2018/683

\section{BACKGROUND}

Periodontal diseases are polymicrobial infection affecting the supporting tissues of the teeth. Dental plaque is considered as the primary aetiological agent for causing periodontal disease. ${ }^{1}$ Plaque exists in a state of biofilm where microbes live as community instead of planktonic state. Biofilm environment provides nutrition and protection to the microorganism. ${ }^{2-3}$

Complete removal of plaque and calculus is more difficult in deep than in shallow pockets; hence, failure of periodontal treatment may be the result of plaque and calculus that remains after therapy is performed. Therefore, the use of

'Financial or Other Competing Interest': None.

Submission 13-02-2018, Peer Review 08-06-2018,

Acceptance 15-06-2018, Published 25-06-2018.

Corresponding Author:

Dr. Keerti Sharma,

H. No. T-23A, Railway Colony,

Tel Tanki Road, Shahjahanpur-242001,

Uttar Pradesh, India.

E-mail: dr.keertisharma@gmail.com

DOI: $10.14260 /$ jemds $/ 2018 / 683$

\section{(c) $(1) Ð$}

drugs to treat plaque associated periodontal disease has been attempted. Successful therapy of periodontitis essentially requires the reduction of microbial levels that are responsible for periodontal infection within the oral cavity. To eliminate bacterial infections, antibiotics are administrated either locally or systemically.

More than 500 different microbial species have been isolated from the human oral cavity, but only a few of them are associated with the disease process. Two of the major pathogens in periodontal disease are A. actinomycetemcomitans and P. gingivalis, as they secrete several potent bioactive virulence factors. A actinomycetemcomitans produces leukotoxins, a large poreforming proteins of the $\mathrm{P}$. gingivalis is a gram-negative protein of the $\mathrm{P}$. gingivalis is a gram-negative anaerobic bacterium involved in pathogenesis of aggressive periodontitis and is frequently found in subgingival flora of diseased subjects. The organism possesses a variety of virulence factors including lipopolysaccharides capsular material and proteases. ${ }^{2}$ Treatment of periodontitis affected patients based on measures for reduction/ eradication of periodontal pathogens and alteration of the systemic and 
local host susceptibility. The antibiotic therapy aims at reinforcement of mechanical periodontal treatment and to support host defences in overcoming the pathogenic role of subgingival microorganism that persists after conventional mechanical therapy. Antibiotics can inhibit or kill periodontal pathogens at sites that are almost impossible to reach by mechanic instrumentation, such as the base of deep periodontal pockets. Furcation areas and within gingival epithelial as well as connective tissues. ${ }^{5}$

A local route of sustained or controlled antimicrobial delivery can achieve high gingival fluid concentrations compared to a systemic drug regimen, which will lead to a significant suppression of subgingival microbiota.6,7 In contrast systemic antibiotics are effective against susceptible periodontal pathogens colonising oral mucosa and other extra dental sites.8,9

Since the systemic route of antimicrobial drug administered is associated with an increased risk of adverse effects and since a more effective concentration of the drug at the affected sites may be obtained by topical application, this system of drug delivery may seem more promising. ${ }^{10}$ Chlorhexidine, iodine and chlorine are examples of antiseptics used in periodontal therapy. ${ }^{11}$ Local administration of chlorhexidine has been demonstrated to be effective as periodontal therapy. Its mechanism of action includes reduction pellicle formation, alteration of bacterial adherence to teeth and alteration of bacterial cell walls which causes cell lysis. ${ }^{12}$

The aim of the study was to investigate the effects of using xanthan based chlorhexidine gel (Ghimas, Italy) used as an adjunct to root planning and curettage in the treatment of patients with advanced aggressive periodontitis.

\section{MATERIALS AND METHODS}

This non-randomised clinical study was a split mouth technique of 6 months duration. Since the study duration was short, the sample size was taken for convenience. Based upon aggressive periodontitis, a total of 5 adult patients were recruited from the outdoor patients Department of Dentistry, Varun Arjun Medical Hospital, Banthra, Shahjahanpur (U. P.) and analysed.

\section{Inclusion Criteria}

- Subjects with aggressive periodontitis with at least one site having 5 - $7 \mathrm{~mm}$ of probing depth.

- Subject in age group of 25 to 40 years well selected.

- Good oral health.

- Localised/ generalised aggressive patients.

\section{Exclusion Criteria}

- Teeth with caries, restoration or endo-perio lesion were not included in the study.

- Habit of tobacco chewing and smoking.

- Aggressive periodontitis.

- History of periodontal therapy 6 months back.

- Subjects unable to provide informed consent.

\section{Clinical Examination}

Five Clinical Parameters were recorded at Baseline and at 1,3 and 6 after treatments, they are-

- Gingival index (GI) (Loe and Silness 1963).

- $\quad$ Probing pocket depth and level of attachment (PPD).
- Clinical attachment level (CAL).

\section{Instruments used are as follows}

The Instruments which were used in this study are as follows-

- Xanthan-based chlorhexidine gel (Ghimas, Italy).

- Mouth mirror.

- Explorer (no. 17/23).

- Tweezers.

- Gloves.

- Mouth mask.

- Cotton gauze.

- William's periodontal probe (Hu-Friedy, USA)

- Sterillium rub-in hand disinfectant (Bode Chemie, Hamburg, Germany).

\section{Clinical Procedure}

A special proforma was designed for present study, so as to have a systemic and methodical recording of all the observation and information. Clinical examination was done on a dental chair, under standard conditions of light, using a mouth mirror, University of North Carolina-15 (UNC-15) probe (Hu- Friedy®) and tweezers and assessment of clinical parameters were carried out. Two sites were selected in subjects, one in test and the other one in control in two different quadrants were non-randomly assigned according to split mouth design.

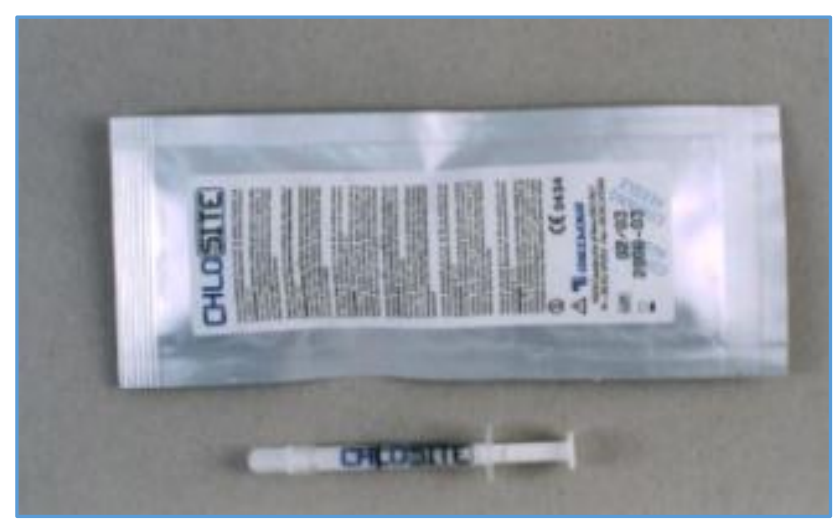

Figure 1. Chlosite Pack

\section{Drug Delivery Devices}

There are Two Possible approaches to improve the Drug Action-

1. Sustained and controlled drug release to reduce or eliminate side effects by improving the therapeutic index.

2. Site specific drug delivery to minimise systemic effects.

\section{Various Drug Delivery Devices are-}

- Fibres.

- Film.

- Injectable systems.

- Gels.

- Strips and compacts.

- Vesicular liposomal systems.

- Microparticle system.

- Nanoparticle system. 
Local route of drug delivery can attain 100-fold higher concentrations of an antimicrobial agent in submicrobial agent in subgingival sites compared with a systemic drug regimen, thereby reducing the total patient dose by over 400 fold avoiding development of drug resistant at non-oral body sites. ${ }^{13}$

\section{Statistical Analysis}

Unpaired t-test was used. Significance was placed at 5\% level of significance, i.e. $\mathrm{p}<0.05$ was considered as significant. Software Stata 13.1 version.

\section{RESULTS}

All subjects showed statistically and clinically significant improvement in full mouth, gingival and plaque indices at both follow-up visits when compared to the baseline levels (Table 1 - 3).

\begin{tabular}{|c|c|c|c|c|}
\hline $\begin{array}{c}\text { Time } \\
\text { Period }\end{array}$ & Test & Control & & \\
\cline { 2 - 5 } & $\begin{array}{c}\text { Mean } \pm \text { SD } \\
\text { (in mm) }\end{array}$ & $\begin{array}{c}\text { Mean } \pm \text { SD } \\
\text { (in mm) }\end{array}$ & T-value & P-value \\
\hline Baseline & $0.13 \pm 0.32$ & $0.09 \pm 0.22$ & 0.000 & 0.001 \\
\hline 1 month & $0.23 \pm 0.12$ & $0.24 \pm 0.21$ & -1.795 & 0.001 \\
\hline 3 months & $0.21 \pm 0.11$ & $0.25 \pm 0.31$ & -3.319 & 0.001 \\
\hline 6 months & $0.16 \pm 0.32$ & $0.18 \pm 0.28$ & -3.393 & 0.002 \\
\hline
\end{tabular}

Table 1. Comparison of Mean PDD Scores between Test and Control Group at baseline 1, 3 and 6 Months

\begin{tabular}{|c|c|c|c|c|}
\hline $\begin{array}{c}\text { Time } \\
\text { Period }\end{array}$ & Test & Control & & \\
\cline { 2 - 5 } & $\begin{array}{c}\text { Mean } \pm \text { SD } \\
\text { (in mm) }\end{array}$ & $\begin{array}{c}\text { Mean } \pm \text { SD } \\
\text { (in mm) }\end{array}$ & T-value & P-value \\
\hline Baseline & $1.31 \pm 1.11$ & $0.21 \pm 1.30$ & -0.969 & 0.001 \\
\hline 1 month & $0.20 \pm 0.01$ & $0.30 \pm 0.02$ & -4.066 & 0.001 \\
\hline 3 months & $0.24 \pm 0.01$ & $0.10 \pm 0.01$ & -2.934 & 0.001 \\
\hline 6 months & $0.25 \pm 0.04$ & $0.41 \pm 0.02$ & -2.618 & 0.002 \\
\hline Table 2. Shows a Comparison of Mean CAL between test \\
and Control Group at baseline 1, 3 and 6 Months \\
\hline
\end{tabular}

\begin{tabular}{|c|c|c|c|c|}
\hline $\begin{array}{c}\text { Time } \\
\text { Period }\end{array}$ & Test & Control & & \\
\cline { 2 - 5 } & $\begin{array}{c}\text { Mean } \pm \text { SD } \\
\text { (in mm) }\end{array}$ & $\begin{array}{c}\text { Mean } \pm \text { SD } \\
\text { (in mm) }\end{array}$ & T-value & P-value \\
\hline Baseline & $0.25 \pm 0.18$ & $0.24 \pm 0.14$ & 0.571 & 0.001 \\
\hline 1 month & $0.15 \pm 0.10$ & $0.26 \pm 0.11$ & -2.163 & 0.001 \\
\hline 3 months & $0.12 \pm 0.15$ & $0.16 \pm 0.12$ & -1.795 & 0.001 \\
\hline 6 months & $0.32 \pm 0.11$ & $0.32 \pm 0.09$ & -2.340 & 0.002 \\
\hline Table 3. Shows a Comparison of Mean GI Scores between \\
Test and Control Group at baseline, 1, 3 and 6 Months \\
\hline
\end{tabular}

\section{DISCUSSION}

Control of plaque is crucial in the treatment of periodontal disease and in the maintenance of oral health. ${ }^{14}$ Primary responsibility for plaque control rests with the patient and mechanical means suffice in most cases. However, in situations in which oral hygiene presents difficulties, the most effective anti-plaque agent, chlorhexidine is useful. The present study based was designed to compare the relative efficacy of subgingivally administered xanthan-based chlorhexidine gel and $0.2 \%$ chlorhexidine irrigation following scaling and root planing (SRP) in the treatment of aggressive periodontitis. Success of periodontal therapy is aimed at eliminating pathogenic microorganism found in dental plaque associated with the tooth surface and other niches in the oral cavity. However, very few patients are able to maintain periodontal health over a lifetime without regular dental care, which consists primarily of oral hygiene instructions and non-surgical therapy. ${ }^{15}$ Since most patients are not skilled in adequate plaque control, clinicians include local and systemic chemotherapeutic agents in their treatment regimen.

The present study was conducted to evaluate the clinical efficacy of administration of CHX in various forms, i.e. irrigation, gel and chip from directly into periodontal pockets as adjuncts to SRP in the management of aggressive periodontitis.

\section{CONCLUSION}

Based on the findings of the study, subgingival irrigation with CHX did not provide clinically significant benefits beyond that achieved with conventional SRP after a 3-month period. Adjunctive use of xanthan-based CHX gel along with conventional non-surgical therapy provide more favourable results in terms of reduction of pocket probing depth and clinical attachment level than SRP alone and thus can be recommended as safe and effective chemotherapeutic agents in the management of patients with aggressive periodontitis.

In conclusion, the publications dealing with efficacy studies suggest that the controlled delivery devices are a useful adjunct to conventional surgical or non-surgical treatments, but are no substitute for these measures. In particular, controlled delivery systems are of interest as an adjunct for aggressive periodontitis. Despite the large number of studies, there are insufficient comparative data to support any one of the local delivery systems as superior to another and several questions related to the optimal use of such new therapies remain.

\section{REFERENCES}

[1] Brogden KA, Guthmiller JM. Polymicrobial diseases. Chap- 8. Washington (DC): ASM Press 2002.

[2] Nahid MA, Rivera M, Lucas A, et al. Polymicrobial infection with periodontal pathogens specifically enhances microRNA miR-146a in ApoE - mice during experimental periodontal disease. Infect Immun 2011;79(4):1597-605.

[3] Venkatesh A, Ramamurthy J. Local drug delivery systems in the treatment of periodontitis - an overview. Int J Pharm Pharm Sci 2012;4(1):30-7.

[4] Herrera D, Sanz M, Jepsen S, et al. A systematic review on the effect of systemic antimicrobials as an adjunct to scaling and root planning in periodontitis patients. Journal of Clinical Periodontology 2002;29(Suppl 3):136-59.

[5] Nakagawa T, Yamada S, Oosuka Y, et al. Clinical and microbiological study of local minocycline delivery (Periocline) following scaling and root planning in recurrent periodontal pockets. Bull Tokyo Dent Coll 1991;32(2):63-70.

[6] Stabholz A, Sela MN, Friedman M, et al. Clinical and microbiological effects of sustained release chlorhexidine in periodontal pockets. J Clin Periodontol 1986;13(8):783-8.

[7] Pedrazzoli V, Kilian M, Karring T. Comparative clinical and microbiological effects of topical subgingival application of metronidazole $25 \%$ dental gel and scaling in the treatment of adult periodontitis. J Clin Periodontol 1992;19(9 Pt 2):715-22. 


\section{Jemds.com}

[8] van Winkelhoff AJ, Rams TE, Slots J. Systemic antibiotic therapy in periodontics. Periodontol 2000 1996;10:45-78.

[9] Slots J, Ting M. Systemic antibiotics in the treatment of periodontal disease. Periodontol 2000 2002;28:10676.

[10] Unsal E, Akkaya M, Walsh TF. Influence of a single application of subgingival chlorhexidine gel or tetracycline paste on the clinical parameters of adult periodontitis patients. J Clin Periodontol 1994;21(5)351-5.

[11] Killoy WJ. The use of locally delivered chlorhexidine in the treatment of periodontics. Clinical results. J Clin Periodontal 1998;25(11 Pt 2):953-8.
Original Research Article

[12] Soskolne WA, Heasman PA, Stabholz A, et al. Sustained local delivery of chlorhexidine in treatment of periodontitis: a multi-center study. J Periodontal 1997;68(1):32-8.

[13] Drisko CH. Non-surgical periodontal therapy. Periodontol 2000 2001;25:77-88.

[14] Lindhe J, Nyman S. Treatment planning. In: Lindhe J, Karring T, Lang NP, eds. Clinical periodontology and implant dentistry. Copenhagen: Munksgaard 1997:420-37.

[15] Goodson JM. Antimicrobial strategies for treatment of periodontal diseases. Periodontol 2000 1994;5:14268. 